\title{
A mulher que comeu o mundo: dramaturgia do ator e multiplicidade da cena
}

\section{Gilberto Icle}

Em outubro de 2006, o grupo brasileiro, Usina do Trabalho Do AutorUTA, estreou seu mais recente trabalho: A mulher que comeu o mundo. Ao seguir a tradição e o costume de trabalho do grupo, esse espetáculo possui uma particularidade, trata-se de uma identidade múltipla, uma vez que o espetáculo se apresenta em duas versões: uma para teatros fechados, em que são usados recursos de iluminação, fundo preto e frontalidade na relação entre atores e público; e a outra, de rua, na qual o espetáculo é apresentado em um círculo no mesmo nível do público, que observa por todos os lados a ação.

A história narrada no espetáculo, encenada dramaticamente, se passa numa pequena cidade, na qual um célebre e rico ladrão, pai de uma moça gorda, chega ao fim em seu metier como larápio ao, para alegria da ínfima e remota cidadela, morrer. A filha, já gorda e corpulenta, devida a inércia em que vivia, só fazia comer. O pai lhe tratava como um bichinho de estimação, a mantinha isolada do mundo, a mimava e tudo lhe alcançava - não obstante lhe alimentar diretamente na boca. É basicamente isso que conta, de forma irônica, a primeira canção do espetáculo. Como não sabia nada fazer, sequer falar - cuja ação, no espetáculo, é substituída por pequenos gritos, grunhidos e balbucios - a moça sai campeando o que comer. Havia já, embora o desconhecimento dos vizinhos, devorado o próprio pai, pois tamanha era a sua dor que a moça come o pai, para tê-lo para sempre consigo. A canibal insaciável nada regurgita e vai a rua a procura do que comer.

Essa narrativa toda já é cantada na música inicial, em que os atores brincam como numa espécie de folguedo popular. Numa das passagens dessa música, especialmente composta por Flávio Oliveira, os atores cantam: 


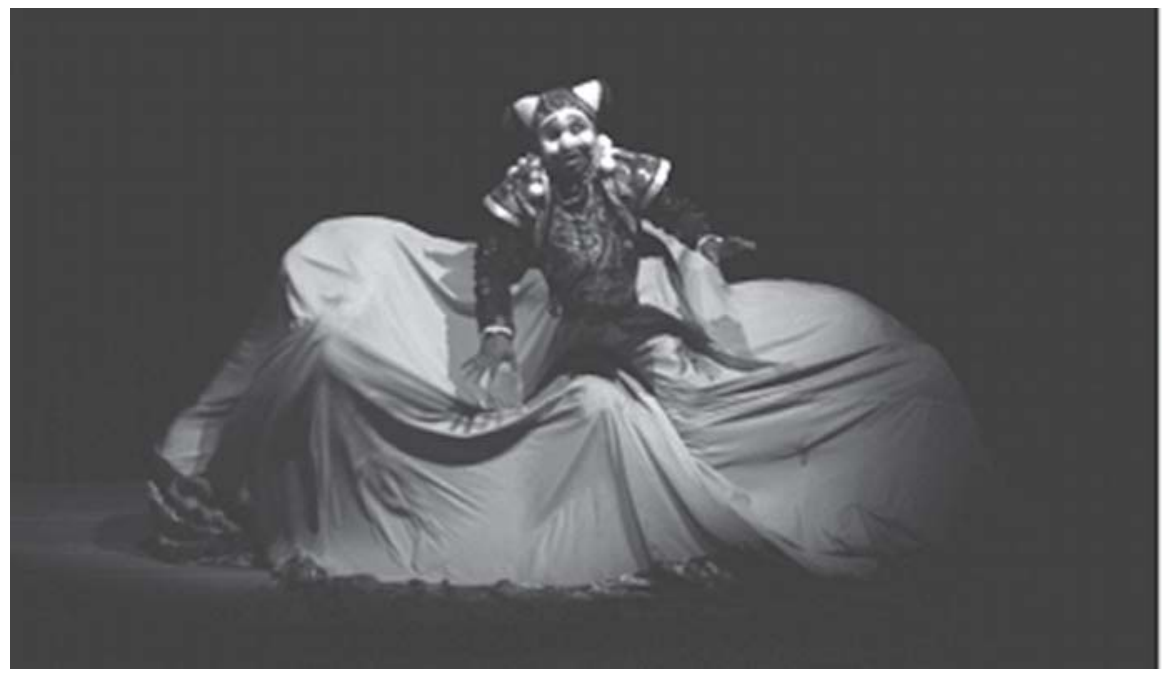

Celina Alcântara como $A$ gorda, em $A$ mulher que comeu o mundo. Foto: Eduardo Essartz Cáceres

Uma gorda enorme e fria tem história engraçada pois comeu tudo que via e no fim ficou sem nada $[\ldots]$ de tão gorda a tal da moça os seus pés não enxergava nem podia andar na roça nem por nada ela falava

A história se alterna em narração musicada e encenação dramática. As cenas que se seguem a abertura deixam entrever que, depois de devorar o pai, a gorda chama a atenção dos vizinhos, tão logo eles percebem que ela não conhece o valor do dinheiro e está disposta a trocar toda a fortuna herdada por comida. Os vizinhos, oportunistas e interesseiros, bajulam-na em troca de suas riquezas. Tentando saciar seu apetite insaciável, ela acaba comendo a cidade inteira, e tudo o que nela havia, até mesmo os vizinhos, devorados pela gula da moça e pela própria mediocridade. Essa empresa é conquistada, também, pelo auxílio libidinoso de um dos vizinhos que se destaca do coro de vizinhos para, ao trair a confiança dos companheiros, fazer as vezes de cúmplice dos desvarios da gorda. 
Noutra passagem, os atores cantam:

No fim das contas, juntinhos

sem piedade e sem dó

vejam lá: gorda e vizinhos

são tudo uma coisa só

Numa paisagem já desterrada e inóspita, a gorda, ao perceber que nada mais havia, chora, pois está sozinha. Suas lágrimas atraem a última das criaturas, a vaca, que algumas cenas antes havia enganado, com o auxílio do coro de vizinhos, as artimanhas famintas da gorda e mudado os desígnios que a todos acometia: ser devorado pela gorda sem pena nem dó. A alegria de ver, finalmente, uma companhia, de tê-la para si como companheira, se confunde na conflituosa ação da gorda, com o desejo de comer. E não sabendo o que fazer, a gorda entrega-se ao desejo flamejante de comer a vaca e a devora: ensopa a vaca e come, come com vontade.

Esse desenrolar dramático, com tratamento cômico-absurdo, é realizado na mise en scène numa seqüência musical ao final do espetáculo, em que os atores, apenas com as cabeças a aparecer por entre a saia gigantesca da gorda, cantam uma espécie de modinha imperial cômica, enquanto a vaca dança e canta no entorno da personagem título. A ação assume um caráter absurdo, visto que a situação é totalmente improvável e o tratamento beira o nonsense, enquanto os atores cantam versos como:

Eis que surge uma companhia, companhia vinda pelas lágrimas choradas, choradas uma vaca gorda das malhadas, das malhadas que no rio de lágrimas sua sede alivia.

A gorda pela vaca toma-se de amores, já não se sente mais vazia, mais vazia; mas sua barriga já produz fortes rumores, será de amor ou fome?... pela nova companhia?

$[\ldots]$

Ela já não sabe mais a quem servir, se à barriga ou ao seu coração; bem devagarzinho ela começa a sentir esta fome enorme, e enorme esta tensão... 
De ter que decidir se como a companheira

ou se deixa viva a vaca idolatrada...

mas como essa fome, já não tem eira nem beira:

a gorda come a vaca ensopada!

A mulher que comeu o mundo é o terceiro espetáculo a compor o projeto Trilogia mascarada, do qual faziam parte outros dois trabalhos do grupo: O ronco do bugio, de 1996, e Mundéu o segredo da noite, de 1998. É importante salientar que, embora nos dois primeiros espetáculos da trilogia, a máscara fosse usada tão somente como maquiagem carregada que deformava a expressão facial do ator, a idéia da máscara como uma modalidade de atuação, já estava presente. Da mesma forma, a multiplicidade de ocupação do espaço é um elemento que, além de mostrar a coerência poética desse coletivo de criação, se deixa entrever no desenvolvimento da idéia de ocupação espacial: no primeiro espetáculo, o espaço da rua é eleito como laboratório no qual são incorporados todos os elementos ali encontrados e uma adaptação da ação, a cada apresentação, permitia que o espaço (uma rua, um chafariz, uma praça, árvores, monumentos) pudesse ser incorporado na própria narrativa dramática; no segundo espetáculo, aparece essa dupla função do espaço cênico, sendo possível adaptá-lo tanto para a rua quanto para o palco à italiana; por fim, no terceiro trabalho da trilogia, as duas versões, palco e rua, são criadas quase como independentes e constituem praticamente duas obras distintas. Sobre as diferenças dessas "duas obras" - e a partir da idéia de dramaturgia do ator - é que vou me esforçar, não obstante meu trabalho como diretor desses trabalhos, em problematizar algumas questões.

Uma primeira diferença fundamental dessas duas versões, e que ao que tudo indica parecem configurar espetáculos distintos, é o tempo de duração de cada uma das versões. Apesar de se tratar dos mesmos atores, do mesmo figurino, da mesma trama de acontecimentos dramáticos, do mesmo tema, a versão de rua dura aproximadamente quarenta minutos, enquanto a versão de sala completa uma hora. Essa variação é conseqüência do modo narrativo de cada uma delas, da maneira da atuação dos atores e das especificidades de relação com o público.

$\mathrm{Na}$ versão de sala conta-se com uma riqueza maior de detalhes e sutilezas, pois o silêncio característico do espaço fechado e a atenção concentrada dos espectadores permite à direção conduzir o olhar do espectador à justeza dos detalhes de tempo e de espaço. A técnica de triangulação (entre ator A, ator B e público) é utilizada em prol da construção de uma tessitura espaço-temporal capaz de articular tanto um nível semântico 


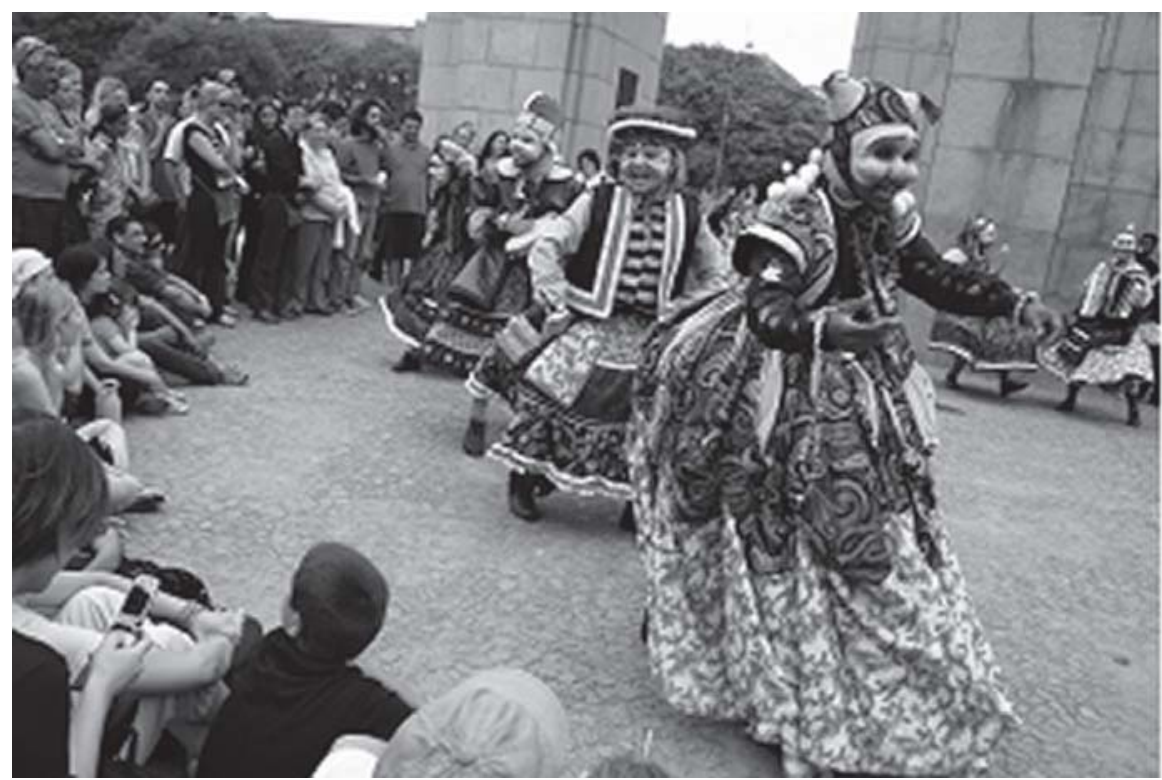

Gisela Habeyche, Thiago Pirajira, Gilberto Icle e Celina Alcântara; ao fundo,

Dedy Ricardo e Ciça Reckziegel em A mulher que comeu o mundo. Foto: Myra Gonçalves

quanto um nível cinestésico-perceptivo. A música que conta a história da personagem principal e do coro de vizinhos é executada ao vivo com diferentes recursos como percussão e acordeón, além das vozes dos atores e outros pequenos objetos percutidos. Esses recursos estão, também, presentes na rua, no entanto, na rua, partes lentas, com intensidades de piano a pianíssimo, bem como, segundas e terceiras vozes estão ausentes ou significativamente diminuídas.

Essas ausências e diminuições da música se fazem sentir na sintetização de determinadas ações que, na rua, sofrem um corte em relação à outra versão. Aquilo que encanta os olhos curiosos e atentos do público que, sentado numa poltrona, observa sem interrupções a ação, não aparece ou passa desapercebido pelo observador da rua que, em muitos casos, divide a atenção com ruídos e eventos que compartem o espaço democrático e multifacetado dos ambientes abertos (Cruciani e Falletti).

Mas se na rua se perdem as sutilezas musicais e os detalhes da ação, ganha-se em intensidade e encanto na surpresa. Ao contrário do espectador que se desloca de casa já com o objetivo certo e programado de assistir determinado espetáculo, paga um ingresso e espera ser ressarcido pelo investimento, o público da rua não tem esse compromisso. É o encanto 
e a sedução da ação teatral que lhe impõe um compromisso momentâneo e efêmero com o espetáculo (Brook). A agudez do instante e a liberdade do evento teatral na rua lhe permitem decidir quando chegar e quando sair do círculo que configura o único acordo tácito entre as duas partes momentaneamente contratadas, atores e público. Dessa forma, a surpresa da irrupção mágica de figuras estranhas e fascinantes, a contar uma história instigante pode ser a única cláusula que assegura, ou não, o interesse prévio e a manutenção da atenção do espectador até o fim da função.

É verdade que esse encanto e surpresa é tão mais fácil quanto mais distante, em termos de costumes e hábitos, os observadores estão dos eventos teatrais, mas, de qualquer modo, se a versão de rua perde em detalhes, ganha em energia que, para além da conquista e sedução do público, deve, antes, dar conta de atingi-lo no seu nível mais elementar: o sensório. É por isso, que os atores em $A$ mulher que comeu o mundo aumentam deliberadamente o desenho das ações, além de multifacetarem em diversas direções o endereçamento das mesmas.

Essa característica do teatro feito para a rua implica não só uma ampliação, uma dilatação da presença física (Barba), mas uma dramaturgia específica e uma trama de acontecimentos que usam a repetição como ferramenta da carpintaria dramática. Em muitas cenas a ação é repetida,

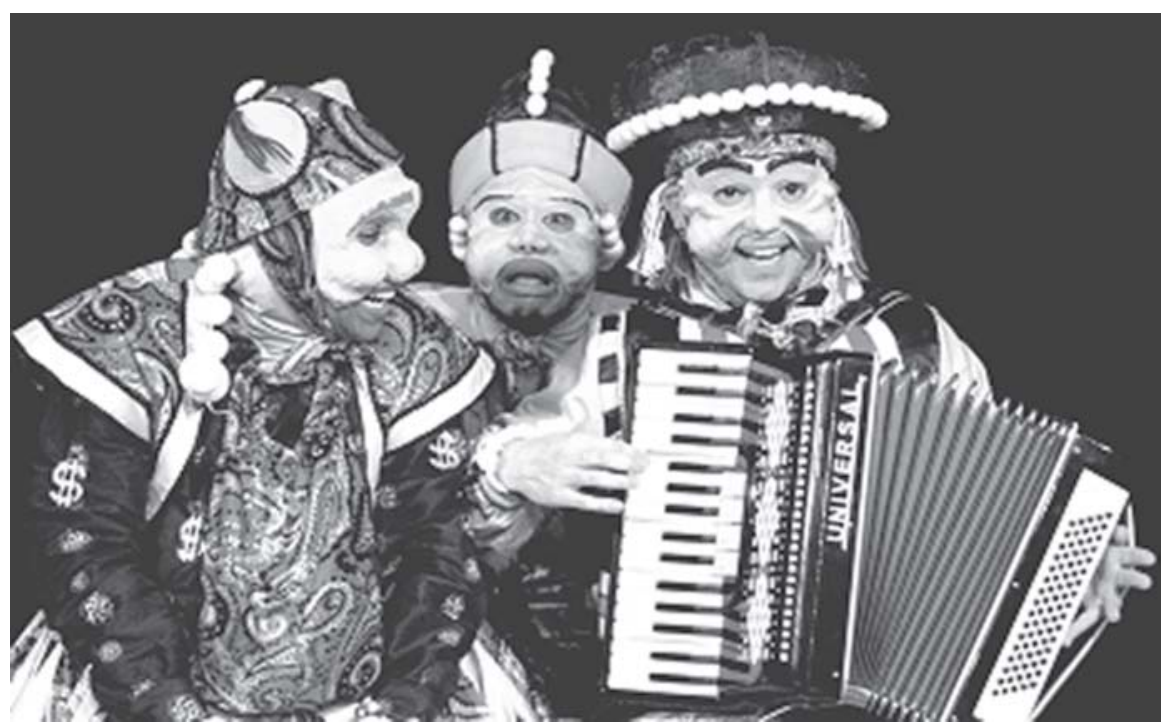

Celina Alcântara, Thiago Pirajira e Gilberto Icle em A Mulher que comeu o mundo. Foto: Myra Gonçalves 
ora para um lado do círculo de espectadores, ora para outro. No mesmo sentido, o efeito de leque, no qual os atores mostram determinado objeto ou realizam uma ação enquanto giram o corpo desenhando no espaço parte de uma circunferência de aproximadamente cento e oitenta graus, cumpre a tarefa de comunicar ao maior número possível de espectadores o que se está fazendo.

O uso da palavra falada, já bastante reduzida na versão de sala, é ainda mais minimizado para o espetáculo de rua, em que a palavra cantada assume totalmente o papel de narração, entrementes os ruídos e barulhos dos atores são potencializados pela configuração do coro. Na versão da rua, a palavra falada se reduz a, tão somente, a tradução que o vizinho personagem que se alia à causa da gorda - faz do gordês, idioma incompreensível que a gorda fala tão gulosamente quanto come. Essas traduções em português são curtas e precisas, quase sempre se reduzindo a uma ou duas palavras, precedidas de longas frases em gordês, cheias de intenções diversificadas. Essa redução das palavras em português que, inicialmente, cumpre propósitos de efeito cômico, se coaduna com precisão às exigências de síntese, precisão e economia de informações pretendidas na versão de rua.

Essa primeira problematização, a discussão sobre as proximidades e distanciamentos entre a versão de rua e a versão de palco, a constituir a possibilidade de se pensar na autonomia dramatúrgica e, portanto, semântica e estética de ambas versões, conduz a uma segunda, e não menos importante, questão, a saber, essa autonomia se constitui justamente no processo de criação, no qual os atores são criadores não só do personagem que lhes é confiado, mas de toda a tessitura cênica que resultará nas distintas formas de interação com o público. A própria imagem de haver um personagem prévio e um alguém que confia ao ator a tarefa de interpretá-lo não é suficiente para dar conta da complexidade em que os atores de $A$ mulher que comeu $o$ mundo se envolveram durante seu processo de criação.

Eis um paradigma descontruído no trabalho da UTA: a idéia de que o ator interpreta um personagem prévio, dado e constituído no discurso da literatura dramática (Aslan). Essa verdade, tão antiga na tradição do teatro euro-americano, quanto insuficiente para a diversidade de possibilidades que o teatro contemporâneo engendra, instituiu um ator falador, muito mais do que um ator autônomo. Esse ator falador (Burnier), como intérprete da obra dramática de um autor que não ele próprio, "decifra" as idéias e ações do texto e serve como intermediário entre o autor do texto e o público. 


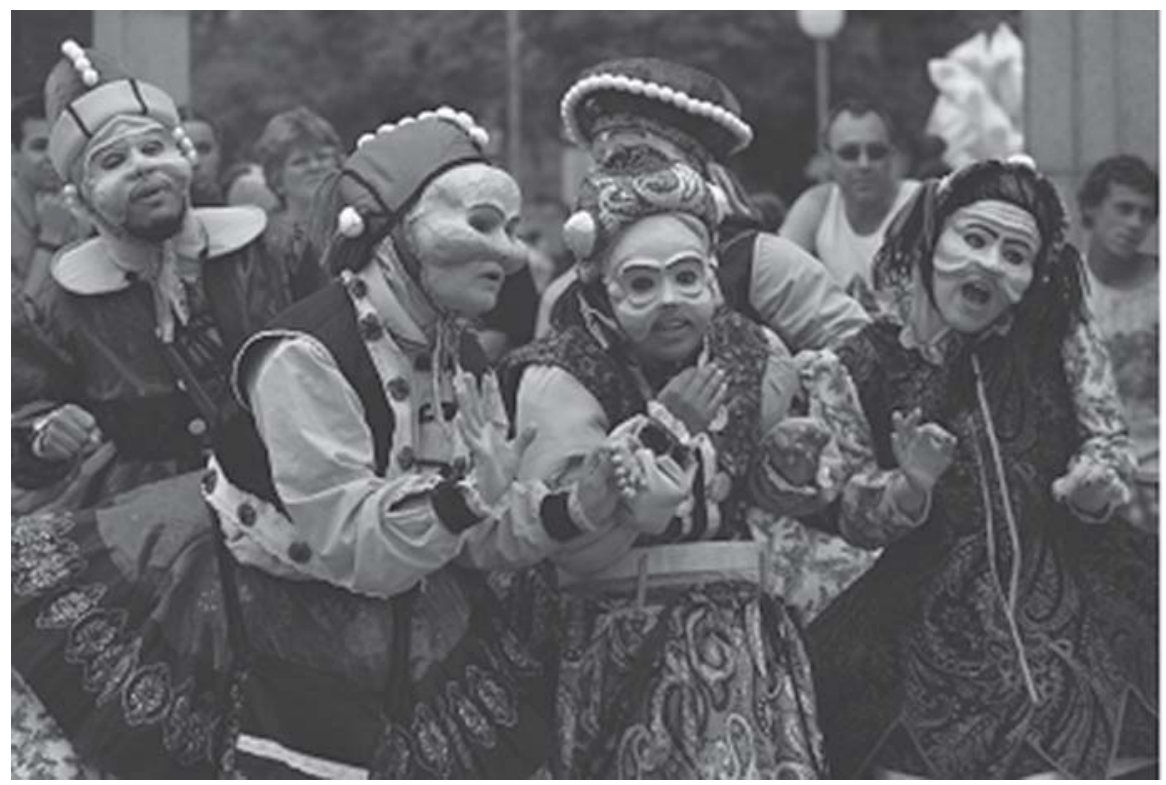

Thiago Pirajira, Ciça Reckziegel, Dedy Ricardo e Gisela Habeyche em A mulher que comeu o mundo. Foto: Myra Gonçalves.

No processo que deu lugar ao espetáculo em tela, não se partiu de um texto prévio, mas, ao contrário, o texto, ou melhor, a tessitura de ações fictícias encadeadas de uma forma verossímil, ainda que muito distante do realismo estético ou de modelos encontrados na realidade, não é um ponto de partida, e sim, de chegada do processo que se coroa na apresentação.

Essa inversão requer do ator uma autoria para si - ou aquilo que Bonfitto (2002) chama de composição - na qual o próprio ator é responsável pela criação e delibera em conjunto com outros criadores (diretor, figurinista, músicos) os caminhos decisórios no processo de criação.

Nessa perspectiva, há uma considerável dispersão das funções do diretor: esse delega ao conjunto dos atores, através dos processos de improvisação e fixação, uma série de funções que tradicionalmente seriam centralizadas no diretor. A descentralização de funções exige que o ator proponha cenas, personagens, abordagens, técnicas, idéias, com as quais o grupo trabalha e articula uma coletividade. Não se trata, contudo, de uma "direção coletiva," tal qual o teatro euro-americano professou a partir da década de sessenta do século passado; mas, uma dispersão aparentemente caótica, que encontra na figura desse diretor, nem tão centralizador quanto 


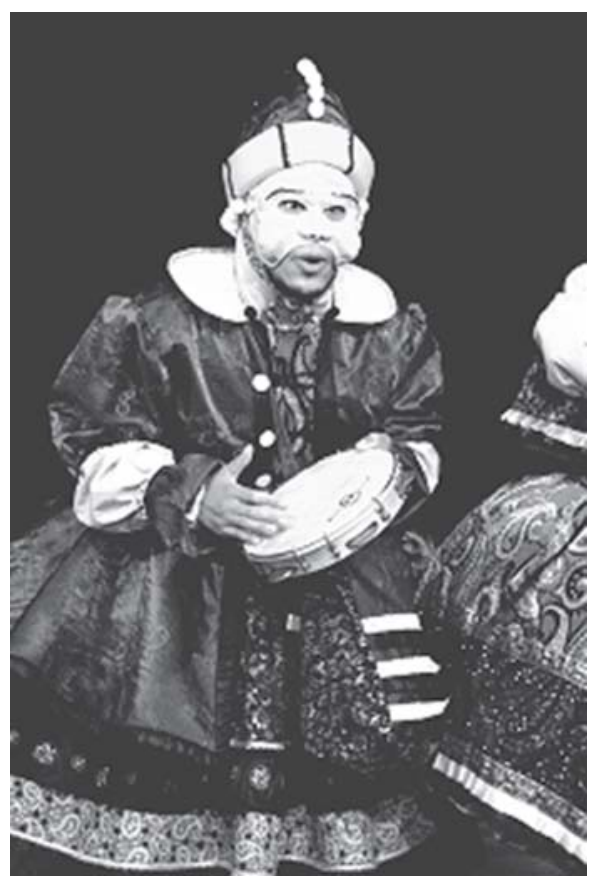

Thiago Pirajira em $A$ mulher que comeu o mundo. Foto: Myra Gonçalves.

nos processos tradicionais - nos quais tudo é decidido pelo poder central da direção - tampouco demasiadamente livre, como em processos ditos "coletivos."

Essa abertura, essa dispersão das funções da direção requerem, assim, uma "dramaturgia do ator" (Barba), ou seja, que a criação da tessitura dramática passe pelas entroncadas e ricas artimanhas daqueles que como criadores são também, executores.

Em $A$ mulher que comeu o mundo, o longo processo de laboratórios e ensaios (cerca de nove meses) definiu, através procedimentos de improvisação, uma série de possibilidades dramáticas. Essas, por sua vez, foram sendo selecionadas pela direção a partir do gosto coletivo e da discussão sobre as intenções da montagem.

É interessante relatar que esses procedimentos de improvisação procedem quase como brincadeiras, durante o processo de criação. Assim, o tema inicial do processo - uma moça gorda que tem uma gula desenfreada é experimentado de muitas formas: ao ser narrado através de mini espetáculos, criados cada um por um dos atores; ao ser parafraseado a partir de clássicos da literatura dramática; ao ser improvisado a partir de situações suscitadas pela improvisação com as máscaras; ou, ao ser decupado de idéias aleatórias para improvisações coletivas.

Não seria estranho perceber, nesse contexto criativo, que é o processo de dramaturgia do ator que conduz a duas obras quase distintas, realizadas simultaneamente, e não como adaptação uma da outra. Essa característica do trabalho da UTA constitui importante recurso criativo e se alinha a componentes cada vez mais autônomos no trabalho teatral. A poética aqui brevemente apresentada implica a dramaturgia do ator à multiplicidade da cena, característica intrínseca desse trabalho. O coletivo de atores, portanto, 
como operadores poéticos, como agentes teatrais ativos, circunscrevem uma possibilidade - diante de tantas outras - de criação, na qual o teatro é espaço, ou melhor dizendo, entre-lugar, de comunicação cultural. A própria prática grupal constitui uma micro-cultura a dar se a ver ao Outro, margeando e delimitando modos de tornar o teatro um fenômeno significativo e solidário.

Universidade Federal do Rio Grande do Sul-UFRGS, Brasil

\section{Referências}

Aslan, Odette. O ator no século XX. São Paulo: Perspectiva, 1994.

Barba, Eugenio. La canoa di carta. Bologna: Il Mulino, 1993. e Nicola, Savarese A arte secreta do ator. São Paulo: Hucitec, 1995.

Bonfitto, Matteo. O ator compositor. São Paulo: Perspectiva, 2002.

Brook, Peter. A porta aberta. Rio de Janeiro: Civilização Brasileira, 1999.

Burnier, Luis Otávio. A arte de ator: da técnica à representação. Campinas: Ed. Unicamp, 2001.

Cruciani, Fabrizio e Clélia Falletti. El teatro de calle: técnica y manejo del espacio. México: Gaceta, 1992.

Icle, Gilberto. Teatro e construção de conhecimento. Porto Alegre/Montenegro: Mercado Aberto/FUNDARTE, 2002. . O ator como xamã. São Paulo: Perspectiva, 2006. 